\title{
POLÍTICA URBANA E PARTICIPAÇÃO: \\ Presença e voz no Conselho da Cidade de Curitiba
}

\section{URBAN POLICY AND CITIZEN PARTICIPATION:}

Presence and voice in the City Council of Curitiba

\author{
Andréa Luiza Curralinho Braga \\ Pontifícia Universidade Católica do Paraná, Escola de Educação e Humanidades, Curitiba, PR, Brasil \\ Huáscar Fialho Pessali \\ Universidade Federal do Paraná, Programa de Pós-Graduação em Políticas Públicas, Curitiba, PR, Brasil
}

R E S U M O : A política urbana em Curitiba tem o Conselho Municipal da Cidade de Curitiba (Concitiba) como instância participativa permanente. Como salienta Graham Smith (2009), o desenho institucional de uma instância dessa natureza é capaz de influenciar a sua capacidade de produzir bens democráticos. Um desses bens é a inclusão, que pode ser dimensionada por meio de dois vetores: presença e voz. Este texto aborda o desenho institucional do Concitiba e dimensiona o quanto produz de inclusão através da presença e da voz ao longo de suas duas primeiras gestóes (2008 a 2013). Com relaçáo à presença, encontramos a predominância regimental e efetiva de dois grupos, o setor público e o setor produtivo. Com relação à voz, notamos amplo provimento de espaço para os grupos representados. Há grande preocupação com a organizaçáo interna do conselho, mas crescem ao longo do tempo manifestaçóes de posiçóes divergentes e projetos conflitantes nos temas de política urbana em si.

P A L A V R A S - C H A V E : Política Urbana. Instituiçóes de Democracia Participativa. Conselho da Cidade de Curitiba. Desenho Institucional. Governança Democrática.

C L A S S I F I C A Ç Ã O J E L : O21; R58; Z18.

A B S T R A C T : Urban policy in Curitiba includes the City Council of Curitiba (Concitiba) as a permanent participatory body. As Graham Smith (2009) indicates, the institutional design of such an instance is capable of influencing its production of democratic goods, in which inclusion is important, and may be assessed through two markers: presence and voice. This paper approaches institutional design of Concitiba and verifies the promotion of inclusion through presence and voice, over its first two terms (2008 to 2012). With regard to presence, two groups demonstrated regimental and effective predominance: the public sector and the productive sector. In terms of voice, there was warranted space for the represented groups to manifest their (mostly conflicting) arguments. Concerns regarding the internal organization of the council were a big issue during its beginnings, but manifestations of divergent positions and conflicting projects in urban policy issues per se eventually outgrew them.

KE Y W O R D S : Urban Policy. Institutions of Participative Democracy. City Council of Curitiba. Institutional Design. Democratic Governance.

JEL CODES: O21;R58;Z18.

DOI: https://doi.org/10.22296/2317-1529.2018v20n3p522 


\section{INTRODUÇÃO}

Os Conselhos são institucionalidades estipuladas pela Constituição Federal de 1988 com vistas a ampliar a soberania popular. Pretende-se que os Conselhos possam influenciar diretamente a construção das políticas públicas (DAGNINO, 2002; TATAGIBA, 2002; GOHN, 2004; CORTES, 2007). No caso da política urbana, espera-se essa atuação por parte dos conselhos das cidades.

Esses conselhos municipais ligados à política urbana começaram a ser formados a partir da deliberação da primeira Conferência Nacional das Cidades, em 2003. O Conselho Nacional das Cidades (Concidades) foi regulamentado em 2004 e, em 2005, produziu as diretrizes para a constituição dos conselhos estaduais e municipais das cidades. Em 2008, o Conselho da Cidade de Curitiba (Concitiba) passou a funcionar.

Tais instituiçôes de democracia participativa são, em grande parte, orientadas por propostas e teorias normativas que justificam a participação do cidadão em processos decisórios de políticas públicas. Por isso é necessário que sejam acompanhadas por teorias explicativas e pesquisas empíricas para que sua dinâmica de funcionamento seja melhor entendida (FUNG, 2007; SHAPIRO, 2003). Isso expóe a necessidade de sistematizar formas empíricas de análise das instituiçôes de democracia participativa para entender seus avanços e limites e, assim, reavaliar a teoria e orientar a prática.

Com a intenção de preencher tal espaço, Graham Smith (2009) propóe um quadro analítico que congrega o que ele chama de bens democráticos. Cada inovação institucional no campo da democracia tem por base um desenho que condiciona as interaçôes e potencializa a evolução de alguns atributos essenciais da democracia em graus distintos. Esses atributos ou bens são: a inclusão, o controle popular, a transparência e o julgamento ponderado. Neste trabalho, vamos nos deter ao bem democrático da inclusão. Nosso intuito é verificar sua manifestação nas duas primeiras gestôes (2008-2013) do Concitiba através de dois vetores: presença e voz dos conselheiros.

\section{CONSELHO DAS CIDADES: A EXPERIÊNCIA RECENTE DE PARTICIPAÇÃO NAS POLÍTICAS URBANAS}

Os Conselhos, como partes de um modelo de gestão pública elaborado na Constituição Federal de 1988, pretendem ampliar a participação e o controle social das políticas públicas. Avritzer e Pereira (2010, p. 1) os caracterizam como "novos espaços de negociação e inter-relação em torno dos atores sociais e do Estado [em que] esses atores debatem suas estratégias e interesses". Por conta de sua rápida disseminação, os Conselhos têm se tornado objetos de interesse do cidadão e também dos pesquisadores brasileiros (TATAGIBA, 2002; AVRITZER, 2002; GOHN, 2004; DAGNINO, 2002; SANTOS JUNIOR, 2007; RIBEIRO, 2004).

No âmbito da política urbana, os conselhos têm sido uma experiência recente como inovaçẫo democrática já presente em outras áreas das políticas públicas (por exemplo, saúde, assistência social e educação) há mais tempo. Mediante o novo desenho participativo previsto na carta magna e especificado no Estatuto das Cidades 
em 2001, o conselho das cidades tornou-se o espaço idealizado para a experiência de participação local voltada ao desenvolvimento urbano. A Conferência Nacional das Cidades em 2003 é o momento em que isso é deliberado. A ela segue a implementação do Conselho Nacional das Cidades (Concidades), regulamentado pelo Decreto 5.031, de 2 de abril de 2004, e, posteriormente, por meio das Resoluçóes n. 13, de 16 de junho de 2004, e a Resolução n. 25, de 18 de março de 2005, que apresentavam as recomendaçôes para a constituição dos conselhos estaduais e municipais das cidades.

A representação no Concidades incluiu diferentes segmentos sociais, entre os quais trabalhadores, organizaçóes não governamentais (ONGs), instituiçôes acadêmicas, movimentos sociais, empresários, e poder público - incluindo os governos federal, estadual e municipal. Esse desenho deveria, entáo, ser seguido pelos estados e municípios, adotando-se a mesma composição do conselho nacional e constituindo-se em instâncias permanentes, consultivas, deliberativas e fiscalizadoras.

Foram atribuições previstas para esses conselhos: "incentivar a criação, a estruturação e o fortalecimento institucional de conselhos afetos à política de desenvolvimento urbano nos níveis municipais, regionais, estaduais e do Distrito Federal" e "[c]riar formas de interlocução entre os conselhos das cidades, nos âmbitos nacional, estadual, do Distrito Federal e municipal, estimulando a troca de experiências" (BRASIL, 2004).

Em 2011, o Brasil possuía 1.231 municípios com conselho municipal de política urbana, o equivalente a $22,1 \%$ do total de municípios (IBGE, 2012). Embora baixa, essa proporção representou um crescimento de $68,3 \%$ com relação a 2005 , quando os conselhos de política urbana estavam presentes em apenas 731 cidades $(13,1 \%$ do total de municípios). Nota-se também a existência de conselhos com práticas semelhantes ao das cidades, embora não originalmente criados para tal, e com uma nomenclatura variada, como Conselho de Desenvolvimento Urbano, Conselho de Desenvolvimento Territorial, Conselho das Cidades, Conselho de Gestão Urbana, entre outros. Mesmo com a atribuição prevista de instâncias permanentes, consultivas, deliberativas e fiscalizadoras, é possível identificar muitos conselhos das cidades sem poder de deliberação, sem definiçôes claras sobre o que deliberar, e sem previsão dos efeitos de suas deliberaçôes sobre a implementação das políticas urbanas.

$\mathrm{Na}$ institucionalizaçáo dos conselhos das cidades está presente o ideário da gestão participativa como aprofundamento da democracia e do controle social na política urbana. Para além do que se considera como avanços, não se pode negar que ainda são muitos os obstáculos e contradiçôes para sua concretização, como apontam diversos autores (CICONELLO, MORONI, 2005; TATAGIBA et al., 2002; TEIXEIRA et al., 2009; SZWAKO, 2012).

Nas obras reunidas em Santos Junior, Ribeiro e Azevedo (2004), por exemplo, é recorrente a identificação de que parte significativa dos segmentos sociais, principalmente os mais vulneráveis, não têm sua agenda de demandas representada nos Conselhos. As graves desigualdades sociais e econômicas dentro dos e entre os municípios impactam na capacidade de articulação, e por isso de inserção, dessas pessoas nas instâncias participativas. Desse modo, o Conselho passa a ter um papel mais burocrático, replicando as estruturas decisórias já existentes, do que de locus que amplia a inserção da sociedade civil no espaço das políticas públicas. Vê-se, assim, a importância de se buscar compreender como se dá a inclusão das pessoas nessas institucionalidades. 


\section{O CONSELHO MUNICIPAL DA CIDADE DE CURITIBA (CONCITIBA)}

Em Curitiba, a Lei Orgânica Municipal de 1990, em seu artigo 79, prevê que a atuação do município atenderá aos princípios da democracia participativa, dispondo sobre a criação dos conselhos municipais nas diversas áreas. Eles serão integrados por representantes populares dos usuários dos serviços públicos, e o município disciplinará sobre sua composição e seu funcionamento.

Atendendo à Lei Orgânica, a implementação do Concitiba ocorreu por meio da Lei n. 12.579, de 18 de dezembro de 2007. Sua primeira reuniáo ocorreu em julho de 2008, e vem se repetindo com frequência bimensal desde então. A lei de criação do Concitiba o descreve como unidade colegiada, fiscalizadora e consultiva, vinculada por linha de tutela e subordinação ao Instituto de Pesquisa e Planejamento Urbano de Curitiba (IPPUC).

As competências antevistas para o Concitiba incluem propor, acompanhar, fiscalizar e avaliar a execução do Plano Diretor de Curitiba, bem como dos planos setoriais, programas e projetos de desenvolvimento urbano dele decorrentes. Além disso, cabe ao Conselho promover e coordenar as Conferências Municipais da Cidade.

Desde a primeira gestão do Concitiba, é discutido o emparelhamento numérico com o Concidades Nacional. A primeira gestáo do Concitiba, de 2008 a 2010, continha 15 conselheiros titulares e o mesmo quantitativo de suplentes. Os conselheiros viriam de quatro segmentos diferentes: seis do Poder Público, três dos setores produtivos envolvidos com o desenvolvimento urbano; três representantes dos setores acadêmico, profissional ou náo governamental (pensando-se em um representante de cada setor citado), e três de instituiçôes ligadas aos movimentos populares ou grupos sociais ligados a políticas públicas urbanísticas (PMC, 2008).

Na segunda gestão, de 2010 a 2013, houve ampliação para 16 representantes titulares e aumento do período de gestão do conselho para três anos. $\mathrm{O}$ segmento antes identificado pela área acadêmica e ao qual eram reservados três assentos passa a ser identificado por "setor acadêmico, profissional, não governamental e dos trabalhadores". Cada um dos quatro subgrupos ali mencionados tem um assento no Conselho (PMC, 2010).

Mencionamos acima que o Concitiba foi implantado com caráter consultivo e fiscalizatório. Em três das seis Conferências Municipais da Cidade de Curitiba, foi deliberada a indicação para que o conselho tivesse maior poder de decisão e incidência na política urbana municipal, assumindo também caráter deliberativo. A deliberação da Conferência, porém, não foi instituída.

Essas são características básicas do desenho institucional do Concitiba. A partir dele, podemos avançar na análise de sua capacidade de inclusão da sociedade civil - um bem democrático importante na construção participativa de políticas de desenvolvimento urbano na cidade de Curitiba. 


\section{DESENHO INSTITUCIONAL E INCLUSÃO COMO BEM DEMOCRÁTICO}

O desenho institucional na democracia participativa tem sido debatido por diversos autores, como Fung (2007), Avritzer (2002), Lüchmann (2007) e Faria; Ribeiro (2011). Esses autores, de modo geral, avaliam que o desenho institucional é uma variável central nas discussôes sobre a dinâmica das instituiçôes participativas. $\mathrm{O}$ desenho ajuda a estabelecer parâmetros, regras e procedimentos para o funcionamento da institucionalidade. Com isso, ele pode favorecer ou prejudicar a qualidade da participação ao condicionar em alguma medida alguns de seus atributos essenciais.

O desenho institucional se expressa como um conjunto de regras, normas e práticas habituais e compartilhadas que dá forma à interação das pessoas num certo campo de ação. Esse conjunto contempla, por exemplo, as atribuiçôes e prerrogativas determinadas por lei aos Conselhos, a forma aceita para escolha ou indicaçáo dos membros, as pessoas envolvidas e sua legitimidade de representação, as açôes que podem ser realizadas, os procedimentos que devem ser respeitados, e como as preferências expressas pelos representantes individuais serão agregadas em decisôes coletivas (FUKS, 2002; LÜCHMANN, 2002).

O desenho institucional de inovaçóes democráticas é o objeto central de análise de Graham Smith (2009). Na obra, Smith esmiúça diversas experiências concretas ao redor do mundo, inclusive o caso do orçamento participativo de Porto Alegre. Para ele, as expectativas dos teóricos democráticos a partir de seus modelos normativos parecem ser muito elevadas, e seria bom que fossem confrontadas com estudos sistemáticos das experiências práticas. No entanto, essas tentativas de aproximação têm se confinado a poucas formas de atividades, deixando de lado grande parte das inovaçôes democráticas e de espaços já institucionalizados de participação. O próprio Smith já havia relacionado 57 exemplos diferentes de institucionalidades participativas em funcionamento ao redor do mundo (Smith, 2005), e ali não estava incluído o exemplo dos Conselhos brasileiros. Isso parece exigir um olhar mais atento sobre as especificidades de cada inovação.

Segundo Smith (2009), as teorias democráticas podem oferecer explicaçôes para a expansão da participação, mas são apenas genéricas e fragmentadas em arquitetar meios de avaliar o potencial das inovaçóes em produzir a democracia esperada. Isso o move a estabelecer um quadro analítico que contemple os atributos mais consensuais entre as teorias normativas. Com isso ele espera aproximar o diálogo entre as teorias ao estabelecer parâmetros comuns de análise, permitindo a comparação e o acompanhamento no tempo das inovaçôes democráticas em termos qualitativos (SMITH, 2009, p. 45).

Os parâmetros delineados por Smith (2009, cap. 1) na confluência das teorias normativas são apresentados como atributos ou bens democráticos. São eles:

i. inclusão, dimensionada pela capacidade de garantir presença e voz à sociedade civil;

ii. controle popular, conferido pela capacidade tanto da institucionalidade participativa de afetar as decisóes no campo de sua atuação quanto da representação civil de influenciar as decisóes tomadas dentro da institucionalidade; 
iii. julgamento ponderado, dimensionado pelo quanto a institucionalidade promove a apreensão de aspectos técnicos por parte dos leigos e também a empatia entre os participantes, ou seja, a explicação sobre como é ver a situaçáo relevante a partir de diferentes posiçôes sociais representadas;

iv. transparência, conferida pela apresentação das açóes e das deliberaçóes tanto ao público interno participante da institucionalidade quanto ao público externo a ela.

$\mathrm{O}$ atributo da inclusão, avaliado neste trabalho, vem da preocupação com a abrangência da participação de grupos sociais na tomada de decisão sobre assuntos públicos. Quando certos grupos sociais manifestam-se sobre a pouca ou nenhuma consideração por eles recebida num regime representativo, avista-se um déficit democrático. Da instituição participativa se espera, portanto, um desenho que reduza tal problema. Se a instituição inclui pessoas ou organizaçóes de modo a apenas replicar o sistema representativo ou a agravar a ausência de grupos de cidadáos do processo decisório, então ela não amplia a democracia. Smith (2009) entende que a participação desigual é uma preocupação persistente e, por isso, a inclusão é um dos indicadores básicos para análise da saúde das instituiçôes participativas. Por isso importa verificar o quanto o desenho de certa instituição participativa pode ajudar a ampliar a participação dos cidadáos por meio de diferentes grupos sociais.

A inclusão é considerada segundo dois vetores. O primeiro é a presença. As regras e os procedimentos de seleção ou entrada e permanência dos participantes, bem como o uso do espaço por eles, são indicadores importantes da inclusão. Smith (2009, p. 21) afirma que a presença:

[...] pode ter um impacto significativo sobre a natureza das decisóes nos espaços da democracia participativa: se os excluídos das decisões políticas não estão presentes, as decisões provavelmente tendem a não responder plenamente às suas preocupaçóes (PHILLIPS 1995: 13). Ao julgar a inclusão de inovações democráticas, teremos de prestar atenção não só nas características formais do mecanismo de seleção, mas também na medida em que, na prática, há incentivos institucionais que motivam o engajamento de cidadáos de todos os grupos sociais, garantindo que um determinado grupo social não esteja marginalizado ou excluído. [...] Simplesmente estar presente não significa necessariamente que os cidadãos estarão dispostos, ou capazes de apresentar as suas contribuiçốes de forma coletiva, mas indica como agem frente ao direito de participar. (SMITH, 2009, p. 21-22 - tradução nossa)

De forma complementar, Smith (2009, p. 21) afirma que a presença de membros de grupos à margem do sistema representativo é condição necessária, mas insuficiente, para garantir inclusão ampliada. Por isso há um segundo vetor na inclusão, a voz. Para explicar a importância da voz, Smith pergunta (idem): "Em que medida o desenho de uma instituição provê de forma igualitária oportunidades substantivas aos cidadãos para exporem suas visôes, serem ouvidos sobre o tema em questão, e terem chances iguais de afetar o resultado a ser ali obtido?"

Definidos os vetores da análise, podemos, então, iniciar a discussão do caso do Concitiba em seu potencial de inclusão. Para o vetor de presença, vamos verificar a participação nas reunióes dos membros designados (conselheiros da sociedade civil e do poder público) e dos eventuais atores externos que participam do processo. Para o 
vetor voz, vamos averiguar (i) principais pontos de pauta nas reuniôes do Conselho; (ii) quem os sugere; (iii) principais participantes envolvidos no debate e relação com os principais temas debatidos.

\section{PRESENÇA NO CONCITIBA}

Para dimensionar o vetor de presença no Concitiba, verificamos a lista de presença das reunióes ordinárias e extraordinárias nas duas primeiras gestóes do Conselho. Foram analisadas ao todo 32 atas, 24 de reunióes ordinárias e oito de reuniōes extraordinárias.

Identificamos, então, as entidades titulares e suplentes presentes às reuniōes, bem como os observadores externos com maior comparecimento. As informaçóes detalhadas dessa identificação estão na Tabela 1.

Tabela 1 - Distribuiçãao das presenças de representantes por setor e gestão

\begin{tabular}{|c|c|c|c|c|c|}
\hline \multirow{3}{*}{ Setor } & \multicolumn{4}{|c|}{ Gestão } & \multirow{3}{*}{$\begin{array}{c}\text { Total Gestão } 1+2 \\
\text { Presença verificada } \\
\text { em atas }\end{array}$} \\
\hline & \multicolumn{2}{|c|}{$1(2008-2010)$} & \multicolumn{2}{|c|}{$2(2010-2013)$} & \\
\hline & $\begin{array}{l}\text { Representaçáo } \\
\text { prevista em } \\
\text { regimento }\end{array}$ & $\begin{array}{c}\text { Presença verificada } \\
\text { em atas }\end{array}$ & $\begin{array}{l}\text { Representação } \\
\text { prevista em } \\
\text { regimento }\end{array}$ & $\begin{array}{c}\text { Presença verificada } \\
\text { em atas }\end{array}$ & \\
\hline Executivo & $33,3 \%$ & $72(35,8 \%)$ & $25 \%$ & $139(40,3 \%)$ & $211(38,6 \%)$ \\
\hline Legislativo & $6,6 \%$ & $6(2,9 \%)$ & $6,25 \%$ & $8(2,3 \%)$ & $14(2,6 \%)$ \\
\hline Setor produtivo & $20 \%$ & $44(21,9 \%)$ & $18,75 \%$ & $68(19,7 \%)$ & $112(20,5 \%)$ \\
\hline Profissionais & $6,6 \%$ & $17(8,5 \%)$ & $6,25 \%$ & $23(6,7 \%)$ & $40(7,3 \%)$ \\
\hline Trabalhadores & Não prevista & $0(0,0 \%)$ & $6,25 \%$ & $21(6,1 \%)$ & $21(3,8 \%)$ \\
\hline Academia & $6,6 \%$ & $11(5,5 \%)$ & $6,25 \%$ & $18(5,2 \%)$ & $29(5,3 \%)$ \\
\hline Movimento social & $20 \%$ & $34(16,9 \%)$ & $18,75 \%$ & $54(15,6 \%)$ & $88(16,1 \%)$ \\
\hline ONGs & $6,6 \%$ & $17(8,5 \%)$ & $6,25 \%$ & $14(4,1 \%)$ & $31(5,7 \%)$ \\
\hline TOTAL & $100 \%$ & 201 & $100 \%$ & 345 & 546 \\
\hline Observador & Não quantificada & $34(16,9 \%$ do total $)$ & & $63(15,4 \%$ do total $)$ & $97(15,1 \%$ do total $)$ \\
\hline TOTAL & & 235 & & 408 & 643 \\
\hline
\end{tabular}

Fonte: Elaboração própria a partir das listas de presença das reunióes ordinárias e extraordinárias do Concitiba.

Conforme apontado na Tabela 1, há nas duas gestôes participação preponderante em números absolutos das categorias com maior número de assentos previstos regimentalmente - o setor público (executivo e legislativo), o setor produtivo e os movimentos sociais. Dentre esses, porém, o grupo dos representantes dos movimentos sociais foi o único a ficar aquém de sua representação proporcional ao longo de ambas as gestóes. Esse grupo teve direito a $20 \%$ e 18,75\% dos assentos nas reuniōes da primeira e segunda gestóes, mas representou apenas 16,9\% e 15,6 dos presentes. Por conta da ausência de representantes desse grupo e de outros (academia e legislativo na primeira gestáo, e também ONGs e trabalhadores na segunda), o setor público e o setor produtivo tiveram representação relativamente maior do que o percentual previsto.

Pelo desenho regimental, as representaçóes previstas do setor público e do setor produtivo somam $60 \%$ do total. Suas presenças ao longo das duas gestôes somam $61,7 \%$, demonstrando a forte participação dos dois grupos. Por outro lado, vê-se que 
a representação da academia, dos trabalhadores, dos movimentos sociais e das ONGs declinou em importância no mesmo período. No caso das ONGs, o declínio se deu até mesmo em números absolutos. Pode-se especular que a dispersão dos interesses desses grupos e a menor representação prevista no desenho venham sendo um elemento de desencorajamento à participaçáo. Como resultado, os dois maiores grupos têm mostrado uma tendência a dominar a representaçáo. Esse pode não ser o resultado esperado na provisão ampla e mais simétrica da presença como bem democrático.

Foi possível também identificar a presença de observadores - pessoas sem atribuiçấo no Concitiba e, portanto, sem direito a voto - nas reunióes. Houve observadores com presença maior que um nas duas gestóes do Conselho. Ao assinar a lista de presenças, observadores podem acrescentar seu eventual vínculo organizacional. Dos 97 observadores presentes em reunióes no período estudado, houve quatro pessoas que se apresentaram como cidadãos, sem identificaçáo de entidade. Dentre os demais, o vínculo organizacional mais presente foi do Ministério Público (36\%). Isso se deve ao seu cumprimento das prerrogativas previstas na Promotoria de Habitaçáo e Urbanismo para acompanhamento dos conselhos atrelados à temática urbana. Também foi expressiva a presença dos servidores e técnicos do Instituto de Pesquisa e Planejamento Urbano de Curitiba (IPPUC), órgão governamental que abriga a estrutura organizacional do Concitiba, com $24 \%$ do total de observadores nas reunióes.

$\mathrm{Na}$ segunda gestão em particular, o número de observadores quase duplicou com relaçáo à primeira. Dentre eles estavam integrantes de dois projetos de pesquisa relativos a assuntos do conselho: o projeto Cidade em Debate e o Observatório das Metrópoles.

\section{VOZ NO CONCITIBA}

Fuks e Perissionotto (2006) destacam quatro momentos do processo deliberativo. O primeiro momento é a apresentação inicial de um determinado tema para a apreciação da plenária. Nos conselhos, esse passo corresponde à composição da pauta. O segundo momento é o estabelecimento da interlocução, materializada nas discussóes feitas no conselho. O terceiro momento é o encaminhamento de proposta sobre o tema em questão para a deliberação. $\mathrm{O}$ quarto corresponde à decisão tomada, ou seja, a aprovação ou não da proposta (FUKS; PERISSIONOTTO, 2006, p. 70).

A análise da voz aqui feita se concentrará nos três primeiros momentos mencionados, tendo sua base empírica sobre as reuniôes do Concitiba. Trabalhamos aqui em duas frentes. Uma delas é a abrangência ou o conteúdo específico da pauta das reunióes, que orienta o que será discutido. De certo modo, como salienta Dagnino (2002), a composição da pauta dá contornos aos posicionamentos, às contraposiçóes e ao alcance da partilha de poder diante de certa configuraçáo de projetos de poder. A outra frente é o quanto se discute cada assunto colocado em pauta e de que forma, indicando maior ou menor interesse e esforço em exercer a voz a respeito de problemas específicos. Em outros termos, enquanto a pauta estabelece limites e possibilidades do uso da voz, o exercício da voz em si em cada tema pautado alude ao empenho em afetálo, assim como pode indicar tentativas de alterar os próprios limites e possibilidades postos pelas pautas. 
Com relação à primeira frente, examinamos as atas das duas gestôes analisadas e categorizamos as pautas mais frequentes em cada uma delas. Isso pode sinalizar as prioridades existentes em cada mandato. A Tabela 2 reúne as informações categorizadas.

Tabela 2 - Categorias de pauta mais frequentes por gestão

\begin{tabular}{lclc}
\hline \multicolumn{2}{c}{ Gestão 1 (2008-2010) } & & \multicolumn{2}{c}{ Gestão 2 (2010-2013) } \\
\hline Categoria & Frequência & Categoria & Frequência \\
\hline Organização do Conselho & 26 & Organização do Conselho & 22 \\
Planejamento Urbano & 8 & Planejamento Urbano & 21 \\
Grandes Projetos & 4 & Grandes Projetos & 10 \\
Habitação & 2 & Outros & 4 \\
Mobilidade & 1 & Habitação & 3 \\
& & Mobilidade & 2 \\
\hline
\end{tabular}

Fonte: Elaboração própria a partir das atas das reuniōes ordinárias e extraordinárias da primeira e segunda gestốes do Concitiba.

Os temas de maior incidência nas pautas do Concitiba nas duas gestôes entre 2008 e 2012 foram aqueles voltados à organização do próprio conselho (47\%). Em segundo lugar estiveram os temas relacionados ao planejamento urbano (27\%). Ou seja, a realidade do Concitiba naquele período se encaixou no que detectaram Almeida e Tatagiba (2012, p. 84-5) para outros conselhos no Brasil: “[...] o principal tema sobre o qual os conselheiros se debruçavam dizia respeito à sua própria dinâmica interna”. Os itens mais arrolados ao controle social, ao desenho da política pública ou às prioridades de investimento público, apesar de serem a maior prerrogativa e finalidade dos conselhos, estiveram menos presentes nos pontos de pautas. É de se esperar que as questóes de organizaçáo e desenho tenham sempre alguma presença em pauta, pois elas se relacionam fortemente com a distribuição de presença, voz e poder naquela própria instância de política. Espera-se também que nos períodos iniciais a isso se some o próprio aprendizado da instituição e de seus primeiros membros como fonte de dúvidas e preocupaçóes sobre a estrutura de funcionamento do conselho. Reforçam a razoabilidade dessa hipótese tanto o aumento relativo da incidência de temas de políticas entre as gestôes quanto a redução relativa e absoluta dos temas de organização interna.

Com relação à outra frente - o quanto se discute cada assunto colocado em pauta - analisamos o conteúdo das discussóes registradas em ata de todas as reuniōes do Concitiba no período. Com auxílio do software $\mathrm{R}$, foi possível construir duas principais categorias de análise para identificar melhor as manifestaçôes. Uma categoria é a do tema da manifestação, dividida de forma binária em manifestação sobre a organização interna e sobre política urbana. Essas foram as duas grandes categorias identificadas nas pautas. Outra categoria é o tipo de manifestação, organizada de forma ternária em pergunta, discussão e proposta. Com isso podemos averiguar a extensão das dúvidas (já que há no conselho importantes questóes técnicas, por exemplo), das trocas de argumentos sobre cada tema, e das finalizaçóes ou encaminhamentos que se sucedem. As categorias e as subsequentes informaçôes a seu respeito estão apresentadas na Tabela 3.

$\mathrm{Na}$ primeira gestão, o tipo de fala mais frequente foi a Discussão da Organização Interna. Os temas predominantes se concentraram em organização de agenda, definição e indicação de pautas, e organização de Câmaras Temáticas. Isso reforça o que foi encontrado a respeito das principais pautas do Concitiba - uma maior 
frequência relativa de temas voltados à organização interna do conselho por conta de sua recente instalação, mas que se amíngua entre as gestôes. Na segunda gestão, a manifestação mais proeminente é a relacionada à Discussão da Política Urbana, com aumento significativo de incidência entre as pautas mais debatidas.

Nas duas gestóes, o segundo tipo de fala mais frequente foi a Proposta sobre Organização Interna do Concitiba. Na primeira gestáo, as manifestaçóes (de todos os tipos) sobre a organização interna somam mais da metade das falas, enquanto na segunda representam pouco mais de um terço.

Tabela 3 - Distribuição dos tipos de fala por gestấo

\begin{tabular}{lccc}
\hline \multirow{2}{*}{ Tipo de fala } & \multicolumn{2}{c}{ Gestão } & \multirow{2}{*}{ TOTAL } \\
\cline { 2 - 3 } & $1(2008-2010)$ & $2(2010-2013)$ & \\
\hline Discussão da Organização Interna & $40(26,3 \%)$ & $29(13,7 \%)$ & $69(19,0 \%)$ \\
Discussão da Política Urbana & $28(18,4 \%)$ & $72(34,1 \%)$ & $100(27,5 \%)$ \\
Pergunta sobre Organização Interna & $4(2,6 \%)$ & $0(0,0 \%)$ & $4(1,1 \%)$ \\
Pergunta sobre Política Urbana & $21(13,8 \%)$ & $30(14,2 \%)$ & $51(14,0 \%)$ \\
Proposta sobre Organização Interna & $37(24,3 \%)$ & $50(23,7 \%)$ & $87(24,0 \%)$ \\
Proposta sobre Política Urbana & $22(14,5 \%)$ & $30(14,2 \%)$ & $52(14,3 \%)$ \\
\hline TOTAL & $152(100,0 \%)$ & $211(100,0 \%)$ & $363(100,0 \%)$ \\
\hline
\end{tabular}

Fonte: Elaboração própria a partir das atas das reuniōes ordinárias e extraordinárias da primeira e segunda gestóes do Concitiba.

Há um percentual distinto, tanto na primeira como na segunda gestão, de perguntas dos conselheiros relacionadas à política urbana. As perguntas sobre a organização interna do conselho são poucas na primeira gestão, e não aparecem na segunda.

Já as discussóes referentes à política urbana ganharam significativo espaço nas manifestaçôes. Elas quase triplicaram em número, passando a ser a categoria de maior vulto na segunda gestão. Alguns temas de política urbana geraram polêmica nas plenárias do Concitiba no período, fazendo avolumar manifestaçôes. Um deles foi o dos planos setoriais. Identificamos algumas que argumentavam pela adequaçáo do conselho como instância para a aprovação dos planos setoriais, e outras pela necessidade de mais ampla participação popular nos processos deliberativos dos planos. Outro tema polêmico foi o dos conflitos fundiários. Alguns conselheiros se manifestaram para identificar o assunto como "caso de polícia", enquanto outros argumentaram ser o tema discutido nacionalmente em vista de resolução do Concidades que prevê a organização de tais políticas de mediação no âmbito dos Estados e municípios. Houve ainda debates sobre a primeira eleição do Conselho Gestor de Habitação de Interesse Social, projetos habitacionais do município, e grandes projetos como cabeamento subterrâneo e obras da Copa do Mundo, que geraram embates e contraposiçóes registradas. Isso sugere um crescimento das disputas de projetos políticos (no caso, projetos de cidade) no âmbito do Conselho.

Nas duas gestôes, identifica-se maior frequência de manifestações originárias dos conselheiros do poder executivo. Num estudo anterior sobre os conselhos gestores de políticas sociais em Curitiba, Fuks e Perissinotto (2006) notaram um claro predomínio dos gestores no uso do espaço de direito e na centralidade das falas. No caso do Concitiba, isso ocorre, em parte, em função do papel central exercido pelos representantes do IPPUC, principalmente no exercício da presidência do conselho 
(assim determinado por sua lei municipal de criação) e na condução da secretaria executiva, bem como em razão do número majoritário de conselheiros do poder executivo. Isso também revela o peso dos aspectos técnicos na dinâmica das discussões no Concitiba, como também notaram Fuks e Perissinotto (2006) para outros casos. À equipe de especialistas é atribuído um papel de destaque na apresentação de informaçốes sobre as açôes e os programas governamentais.

Apresentamos na Tabela 4 as manifestaçóes por setor representado no Concitiba ao longo da sua primeira gestão. Vê-se ali que o poder executivo incide com maior frequência em temas relacionados à organização interna. E ele também é quem mais se manifesta com propostas no mesmo tema, enquanto alguns outros grupos representados se manifestam (ONG, Legislativo e Movimento social) em poucas ocasiôes com dúvidas e questionamentos.

Tabela 4 - Distribuição da voz dos representantes por setor na primeira gestão do Concitiba (2008-2010)

\begin{tabular}{|c|c|c|c|c|c|c|c|}
\hline \multirow[b]{2}{*}{ Setor } & \multicolumn{6}{|c|}{ Tipo de Fala } & \multirow[b]{2}{*}{ TOTAL } \\
\hline & $\begin{array}{c}\text { Discussão da } \\
\text { Organização } \\
\text { Interna } \\
\end{array}$ & $\begin{array}{c}\text { Discussão } \\
\text { da Política } \\
\text { Urbana } \\
\end{array}$ & $\begin{array}{c}\text { Pergunta sobre } \\
\text { Organização } \\
\text { Interna } \\
\end{array}$ & $\begin{array}{c}\text { Pergunta } \\
\text { sobre Política } \\
\text { Urbana }\end{array}$ & $\begin{array}{c}\text { Proposta sobre } \\
\text { Organizaçáo } \\
\text { Interna } \\
\end{array}$ & $\begin{array}{c}\text { Proposta } \\
\text { sobre Política } \\
\text { Urbana } \\
\end{array}$ & \\
\hline Academia & 0 & 0 & 0 & 2 & 2 & 2 & 6 \\
\hline Executivo & 15 & 2 & 0 & 1 & 21 & 5 & 44 \\
\hline Legislativo & 1 & 1 & 1 & 0 & 0 & 1 & 4 \\
\hline Movimento social & 4 & 3 & 1 & 5 & 5 & 1 & 19 \\
\hline Observador & 4 & 1 & 0 & 2 & 0 & 0 & 7 \\
\hline ONG & 8 & 8 & 2 & 3 & 6 & 3 & 30 \\
\hline Profissionais & 3 & 1 & 0 & 1 & 0 & 0 & 5 \\
\hline Setor produtivo & 5 & 12 & 0 & 7 & 3 & 10 & 37 \\
\hline TOTAL & 40 & 28 & 4 & 21 & 37 & 22 & 152 \\
\hline
\end{tabular}

Fonte: Elaboração própria a partir das atas das reuniôes ordinárias e extraordinárias da primeira gestão do Concitiba.

O setor produtivo se manifestou com maior frequência na discussão da política urbana, principalmente no debate voltado à moradia e à concomitante produção mercantil de habitaçôes. $\mathrm{Na}$ discussão sobre a organização interna, remetem à Lei de criação do Concitiba, propondo a ampliaçáo da representaçáo dos empresários, argumentando que o segmento tem atuação proativa no conselho. Nas propostas relacionadas à política urbana, indicam como temas prioritários a implementação de cabeamento subterrâneo e a ampliação do potencial construtivo no zoneamento municipal.

As ONGs manifestaram-se sobre a organização interna do Conselho a respeito da criação das Câmaras Temáticas e também a respeito da inclusão de representantes dos trabalhadores no Concitiba, como estabelecem as diretrizes da Resolução 13 do Concidades Nacional. Suas manifestaçôes propositivas para política urbana se voltam para a efetivação de instrumentos urbanísticos do Estatuto das Cidades, como usucapião coletivo, regularização fundiária e participação popular na definição dos planos setoriais.

Os movimentos sociais também se manifestaram nas discussões já mencionadas sobre a organização interna do Concitiba. Sobre a política urbana, se manifestaram principalmente a respeito da eleição do Conselho Gestor de Habitação de Interesse 
Social (CGHIS) e da aplicação do fundo de habitação. As demais categorias se manifestaram com pouca frequência.

A Tabela 5 replica as categorias da Tabela 4, agora com informação referente à segunda gestáo do Concitiba. Há ali uma maior heterogeneidade nas discussóes da sociedade civil e uma frequência ampliada nos campos de Discussão da Política Urbana e de Proposta sobre Política Urbana. Ao mesmo tempo, como se poderia esperar, houve uma diminuição de manifestaçóes relacionadas à discussão, a propostas e a perguntas em torno da organização interna do Conselho. Náo houve nenhuma manifestaçáo que expressasse dúvidas sobre a organização interna do conselho. Isso pode indicar maior conhecimento dos procedimentos do Concitiba por parte dos conselheiros, bem como uma acomodação da estrutura formada na primeira gestâo através do estabelecimento de seu regimento e de canais de comunicação internos e entre os representantes.

As falas mais expressivas do poder executivo na segunda gestáo recomendam grupo de trabalho para revisão do regimento interno do conselho, que mais tarde se concretizou para aproximar sua composição à do Concidades e para contemplar a realização das conferências municipais (PMC, 2013). Nas propostas para a política urbana, sobressaem falas sugerindo açóes conjuntas com a região metropolitana de Curitiba, moção de apoio ao Plano Multimodal e indicação de estudo sobre cabeamento subterrâneo.

No período das duas primeiras gestôes do Concitiba, constata-se que as propostas apresentadas pelos conselheiros do poder executivo tinham vinculação direta com as demandas do poder público municipal. Como destaque, os conselheiros do poder executivo incidem nas pautas de definição dos Planos Setoriais para implementação posterior. Também apresentam demandas vinculadas à Companhia de Habitação do município (COHAB-CT), indicando o debate sobre a política de habitação de interesse social e a definição de critérios no acesso ao programa Minha Casa, Minha Vida. Ainda, os conselheiros do poder executivo solicitam a verificação de valor para implementação do cabeamento subterrâneo, o que reverbera em Resolução no conselho e, depois, na execução dessas obras no âmbito do município.

No tocante à atuação do poder legislativo no Concitiba, constata-se sua reduzida incidência de propostas. $\mathrm{Na}$ primeira gestão, foi localizada uma discussão referente à política urbana centrada no tema cabeamento subterrâneo. Decidiu-se ali indicar o debate para a comissão de urbanismo na câmara de vereadores. A discussão foi de fato levada à câmara e a lei sobre cabeamento subterrâneo foi aprovada em 9 de dezembro de 2014. O projeto de lei obriga a substituiçấo do cabeamento aéreo pela rede subterrânea no município e atinge as empresas e concessionárias responsáveis pela fiação de energia elétrica, de telefonia, de comunicação de dados via fibra óptica e de televisão a cabo, dentre outras. Também apresentaram proposta para formulação de política de resíduos sólidos no município. 
Tabela 5 - Distribuição da voz dos representantes por setor na segunda gestão do Concitiba (2010-2013)

\begin{tabular}{|c|c|c|c|c|c|c|c|}
\hline \multirow[b]{2}{*}{ Setor } & \multicolumn{6}{|c|}{ Tipo de Fala } & \multirow[t]{2}{*}{ TOTAL } \\
\hline & $\begin{array}{c}\text { Discussão da } \\
\text { Organização } \\
\text { Interna }\end{array}$ & $\begin{array}{c}\text { Discussão } \\
\text { da Política } \\
\text { Urbana }\end{array}$ & $\begin{array}{l}\text { Pergunta sobre } \\
\text { Organização } \\
\text { Interna }\end{array}$ & $\begin{array}{c}\text { Pergunta } \\
\text { sobre Política } \\
\text { Urbana }\end{array}$ & $\begin{array}{l}\text { Proposta sobre } \\
\text { Organização } \\
\text { Interna }\end{array}$ & $\begin{array}{c}\text { Proposta } \\
\text { sobre Política } \\
\text { Urbana }\end{array}$ & \\
\hline Academia & 0 & 0 & 0 & 0 & 0 & 1 & 1 \\
\hline Executivo & 9 & 36 & 0 & 4 & 12 & 9 & 70 \\
\hline Legislativo & 0 & 2 & 0 & 0 & 1 & 0 & 3 \\
\hline Movimento social & 2 & 5 & 0 & 3 & 7 & 0 & 17 \\
\hline Observador & 0 & 0 & 0 & 0 & 1 & 0 & 1 \\
\hline ONG & 2 & 4 & 0 & 4 & 0 & 2 & 12 \\
\hline Profissionais & 6 & 5 & 0 & 8 & 8 & 1 & 28 \\
\hline Setor produtivo & 7 & 12 & 0 & 7 & 15 & 14 & 55 \\
\hline Trabalhadores & 3 & 8 & 0 & 4 & 6 & 3 & 24 \\
\hline TOTAL & 29 & 72 & 0 & 30 & 50 & 30 & 211 \\
\hline
\end{tabular}

Fonte: Fonte: Elaboração própria a partir das atas das reuniôes ordinárias e extraordinárias da segunda gestão do Concitiba.

O setor produtivo manifesta-se amplamente nas várias categorias (exceto nas dúvidas sobre a organização interna). São mais frequentes suas manifestaçôes em duas delas. A primeira envolve propostas para a revisão do regimento interno voltada à estruturação das conferências, reagindo às discussôes correlatas provocadas pelo poder executivo. A segunda envolve propostas afins à política urbana, principalmente nos temas do Plano Municipal sobre Patrimônio Histórico, de revitalização (intensificar a punição para as pichaçôes de muros) e, com maior frequência, no tema do cabeamento subterrâneo, intensificando suas demandas e proposiçóes manifestas no período da primeira gestão.

As entidades profissionais, cuja representação pouco se manifestou na primeira gestáo do conselho, têm comportamento distinto na segunda gestão. Suas manifestaçôes estão em quase todas as categorias. Houve, por exemplo, uma proposta para a política urbana envolvendo a mediação de conflitos fundiários. Houve também propostas para a organização interna do conselho, dentre as quais uma referente ao acompanhamento da aplicação dos recursos do Fundo Municipal de Habitação de Interesse Social e outra que elaborava a exigência de se adicionar caráter deliberativo ao conselho.

O segmento dos trabalhadores, incluído na representaçáo da segunda gestáo, teve significativa participação nas reunióes. Suas manifestaçóes foram frequentes, discutindo a política urbana e formulando propostas. Estas se voltaram à definição para critérios locais do programa Minha Casa, Minha Vida, à articulação com o Concidades Estadual, e à resoluçáo sobre conflitos fundiários. Em discussão principalmente com o setor produtivo a respeito da pichação do patrimônio público, propôs açóes de cunho socioeducativo.

Os movimentos sociais se manifestaram nas duas grandes categorias, mas suas propostas ficaram concentradas não na política urbana, mas na organização interna do Conselho. Elas eram relacionadas à revisão da lei do Concitiba e, assim como ocorreu com os representantes das entidades profissionais, propuseram conferir caráter deliberativo ao conselho. Os demais grupos representados (Academia, Legislativo) e os Observadores fizeram poucas intervençôes.

Percebe-se que no Concitiba os diferentes segmentos da sociedade civil e do 
Estado se engajam em temas distintos e suas propostas se voltam a objetos e direçóes que dificilmente coincidem. Isso acrescenta evidência à concepção de que as relações no conselho espelham disputas de projetos políticos, sinalizam alianças que precisam ser construídas para consolidar tais projetos, e explicitam as dificuldades dos projetos minoritários e esparsos em negociar espaços. Os representantes da sociedade civil não aparecem como portadores de uma racionalidade unificada e imparcial, como se corporificassem o "bem comum" ou o "interesse público". Como havia notado Tatagiba (2002), eles aparecem, ao contrário, como portadores de concepções situadas e parciais do que deve ser o "bem comum", e que são na maior parte do tempo conflitantes e até mesmo antagônicas entre si.

\section{CONSIDERAÇÕES FINAIS}

Na investigação sobre as instituições de democracia participativa, um dos desafios está em transformar as análises políticas, teóricas e empíricas dessas experiências em parâmetros que ajudem a acompanhar a provisão esperada de participação social. O quadro analítico de Graham Smith (2009) sobre desenho institucional e bens democráticos produzidos é justamente orientado a tal propósito.

Aplicou-se aqui parte do quadro analítico de Smith, tendo por foco a produção da inclusão no Concitiba. Como toda instituição de democracia participativa, "[...] os conselhos representam um importante avanço na construção de formas mais democráticas de gestão nos negócios públicos, mas seu potencial e âmbito de atuação são naturalmente limitados" (TATAGIBA, 2002, p. 100). O acompanhamento da produção de bens democráticos por conselhos como o Concitiba é, portanto, um meio de dimensionar seus potenciais e limitaçôes. Evidencia-se que a análise sobre bens democráticos com enfoque na produção de Smith é uma experiência inovadora no contexto brasileiro. Há o projeto do Observatório dos Conselhos, no Programa de Pós-Graduação em Políticas Públicas da Universidade Federal do Paraná, que tem como proposta replicar a experiência de análise dos bens democráticos em outros espaços participativos no contexto local e nacional.

$\mathrm{Na}$ apreciação sobre a arquitetura participativa, observa-se o desenho do Concitiba envolto de uma multiplicidade de fatores, abarcando a variação nas regras e as relaçôes dos conselheiros, e perpassando as requisiçóes postas na arena pública, propagadas por interesses diferenciados e divergentes. Há um jogo político de forças em disputa, dos segmentos e atores presentes no conselho, que buscam defender suas propostas e ressaltam as contraposiçôes presentes em vários momentos dos debates.

$\mathrm{Na}$ identificação dos representantes que têm assento e tiveram presença no conselho, viu-se que o desenho estabelece o poder público como maior detentor de vagas e votos, com destaque para o IPPUC. A ele segue o setor produtivo, maior parte representada da sociedade civil. Os dois grupos têm vagas e votos que superam a metade do total na primeira gestáo, e exatamente a metade na segunda gestáo. Ambos mantiveram as mais elevadas presenças nas duas gestóes. Verificou-se que os outros segmentos representados tiveram presença menor. Isso implica que, no cômputo médio, o setor público e o setor produtivo juntos tiveram votos em quantidade mais do que suficiente para estabelecer maioria, mesmo quando a proporção regimental de assentos diminuiu durante a segunda gestão. Esse é um facilitador clássico de coligação 
Andréa Luiza Curralinho Braga é Mestre em Políticas Públicas pela Universidade Federal do Paraná. Professora do Curso de Serviço Social da Pontifícia Universidade Católica do Paraná.

E-mail: andrea.braga@pucpr. br

ORCID: http://orcid.org/0000 0002-0233-3496

Huáscar Fialho Pessali é Doutor em Economia (University of Hertfordshire). Professor do Programa de Pós-graduação em Políticas Públicas da UFPR. Huáscar agradece o apoio financeiro do CNPq por meio da bolsa PQ 306568/2012-8.

E-mail: pessali@ufpr.br ORCID: http://orcid.org/00000002-5770-4653

Artigo recebido em 27 de agosto de 2017 e aprovado para publicação em 09 de abril de 2018.

Artigo licenciado sob Licença Creative Commons (CC-BY). política. Se isso de fato ocorreu, não nos foi possível ainda analisar - o que poderia ser explorado, por exemplo, a partir da verificação de posiçóes convergentes nos debates e nas deliberaçóes. Resta aí um exercício de interesse.

Quanto à voz no Concitiba, o registro das manifestaçóes nas reuniôes expressou a pluralidade e diversidade de interesses. O desenho, nesse aspecto, mostrou ampla provisáo para manifestaçóes tanto sobre o próprio desenho quanto ao objeto de interesse - a cidade e as políticas púbicas a seu respeito. A análise do conteúdo das falas confirmou a heterogeneidade de interesses dos segmentos representados, expressando posições divergentes, ênfases e prioridades distintas. Ao analisar as falas dos conselheiros, verifica-se o jogo de forças que institui o terreno de disputa no qual se dá esse processo. Assim, pluralidade de conhecimentos, interesses, concepçôes políticas e ideológicas no âmbito do Conselho foram ali expressas.

Bom será poder acompanhar as gestôes seguintes para verificar se outras mudanças no desenho, que já se sabe terem ocorrido, vieram acompanhadas de mudanças nos padróes de manifestação. Caberia também verificar se o comportamento dos participantes das primeiras gestôes quanto ao uso da voz criou um padrão de interação que se instituiu mais solidamente, sendo reforçado pelos hábitos.

Embora os conselhos em geral não possam ser compreendidos como o lugar último da realização da política, a recente experiência do Concitiba mostra uma ampliação do espaço institucionalizado de interação, discussão e decisão, complementando outras formas de se fazer política urbana na cidade. Acompanhar sua produção de bens democráticos essenciais - não só a inclusão, mas também o controle popular, a transparência e o julgamento ponderado - e associá-los às decisões e ações consequentes é uma forma de conjugar o esforço teórico com a prática democrática nas políticas urbanas.

\section{REFERÊNCIAS BIBLIOGRÁFICAS}

AVRITZER, L. (Org.). Experiências nacionais de participação social. Belo Horizonte: Cortez Editora, 2010

SANTOS, B. S. Para ampliar el canon de la democracia. In: SANTOS, B. S. (Org.). Democratizar la democracia: los caminos de la democracia participativa. Rio de Janeiro: Civilização Brasileira, 2002.

CICONELlO, A.; MORONI, J. 'Participação social no governo Lula. Avançamos?', in ABONG (ed.) A ABONG nas Conferências 2005: Criança e Adolescente - Assistência Social. Brasília: ABONG, 2005.

CORTES, S. V. Viabilizando a participação em conselhos de política pública municipais: arcabouço institucional, organização do movimento popular e policy communities. Rio de Janeiro: Fiocruz, 2007.

DAGNINO, E. Sociedade civil e espaços públicos no Brasil. In: E. DAGNINO (Org.). Sociedade civil e espaços públicos no Brasil. São Paulo: Paz e Terra, 2002.

FARIA C. F. O Estado em movimento: complexidade social e participação política no Rio Grande do Sul. Tese (Doutorado). Programa de Pós-Graduação em Ciência Política. Universidade Federal de Minas Gerais, Belo Horizonte, 2005.

; RIBEIRO, U. C. Desenho institucional: variáveis relevantes e seus efeitos sobre o processo participativo. In: PIRES, R. (Org.). Efetividade das instituiçóes participativas no Brasil: estratégias de avaliação. Brasília: IPEA, 2011, v. 7, p. 125-136. 
FUKS, M. Participação política em conselhos gestores de políticas sociais no Paraná. In: PERISSINOTTO, R. M. \& FUKS, M. (orgs.). Democracia: teoria e prática. Relume Dumará, 2002.

; PERISSINOTTO, R. Recursos, decisão e poder: conselhos gestores de políticas públicas de Curitiba. Revista Brasileira de Ciências Sociais, v. 21, n. 60, fev.2006.

FUNG. A. Democratic Theory and Political Science: a pragmatic method of constructing engagement. American Journal of Political Science, n. 58, 2007, p. 101-443.

GOHN, M. G. Conselhos Gestores e Participação Sociopolítica. 3a ed. São Paulo: Cortez, 2011. Empoderamento e participação da comunidade em políticas sociais. Saúde e Sociedade, v. 13, n. 2, p. 20-31, maio-agosto, 2004.

LUCHMANN. L. H. Os conselhos gestores de políticas públicas: desafios do desenho institucional. Ciências Sociais Unisinos, n. 161, 2002, p. 43-79.

A representação das experiências de participação. Lua Nova, v. 70, p. 139-170, 2007.

PMC-PREFEITURA MUNICIPAL DE CURITIBA. Decreto no. 108 - Nomeia membros titulares e suplentes do Conselho da Cidade de Curitiba-Concitiba. Diário Oficial do Município, 26 de fevereiro de 2008.

PMC-PREFEITURA MUNICIPAL DE CURITIBA. Decreto no. 678 - Nomeia membros titulares e suplentes do Conselho da Cidade de Curitiba-Concitiba. Diário Oficial do Município, 15 de junho de 2010.

PMC-PREFEITURA MUNICIPAL DE CURITIBA. Lei $n^{\circ} 14314$ - Altera dispositivos da Lei no 12.579... Diário Oficial do Município, 19 de setembro de 2013.

PUPO, S.; BUENO, L. M. M. Entre avanços e retrocessos: as contradiçóes ou armadilhas da participação no planejamento urbano participativo. Revista Brasileira de Estudos Urbanos e Regionais, v. 14, n. 1, 2012, p. 135-152.

SANTOS JUNIOR, O. A. Cidade, cidadania e planejamento urbano: desafios na perspectiva da reforma urbana. In Feldman, S.; Fernandes, A. (Orgs.). O urbano e o regional no Brasil Contemporâneo: mutações, tensões, desafios. Salvador: EDUFBA, 2007. p. 293-314.

SANTOS JUNIOR, O. A.; RIBEIRO, L. C.; AZEVEDO, S. (orgs.). Governança democrática e poder local: a experiência dos conselhos municipais no Brasil. Rio de Janeiro: Revan, Fase, 2004.

SHAPIRO, I. The state of Democratic Theory. Londres: Princeton University Press, 2003.

SMITH, G. Beyond the ballot: 57 democratic innovations from around the world. Londres: The POWER Inquiry, 2005.

. Democratic innovations: designing institutions for citizen participation. Cambridge: Cambridge University Press, 2009.

SZWAKO, J. Participar vale a pena, mas...: a democracia participativa brasileira vista pelas lentes da utopia. In: SOUTO, A. L.; PAZ, R. (Orgs.). Novas lentes sobre a participação: utopias, agendas e desafios. São Paulo: Instituto Pólis, 2012.

TATAGIBA, L. Os conselhos gestores e a democratização das políticas públicas no Brasil. In: DAGNINO, E. (org.). Sociedade civil e espaços públicos no Brasil. São Paulo: Paz e Terra, 2002.

TATAGIBA, L.; SILVA, M. Z.; PINTO, R. C.; SAMPAIO, A. P. Descentralização, participação e cooptação: limites e possibilidades da governança urbana no Brasil. O caso de Vitória/ES. Ciências Sociais Unisinos, v. 38, n.161, p. 123-147, 2002.

TEIXEIRA, A.; MORONI, J. \& MARX, V. Políticas de participação e novas institucionalidades democráticas no contexto brasileiro recente. In: SERAFIM, L.; MORONI, J. A. Sociedade civil e novas institucionalidades na América Latina: dilemas e perspectivas. São Paulo: Instituto Pólis e Inesc, pp. 81-98, 2009. 